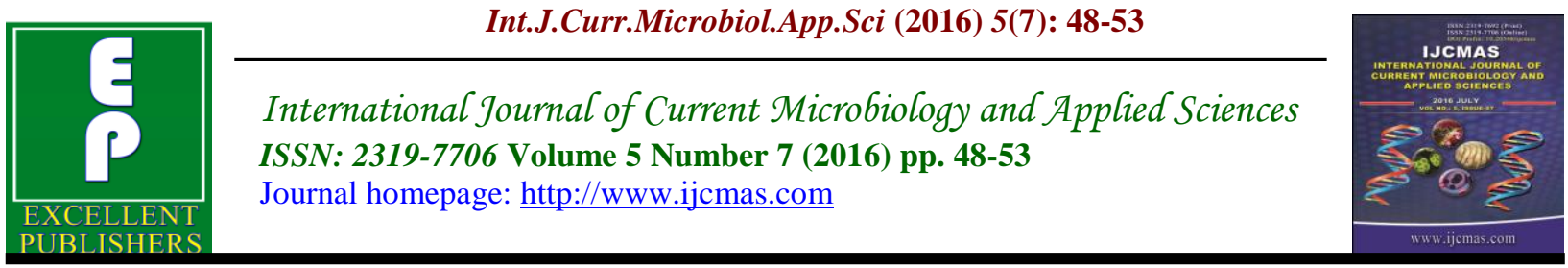

Original Research Article

http://dx.doi.org/10.20546/ijcmas.2016.507.003

\title{
Isolation of Multiple Drug Resistant (MDR) Bacteria from Hospital Environment
}

\author{
Madhumita Ghosh Dastidar ${ }^{1}$ and M. Razia $^{2 *}$ \\ ${ }^{1}$ Department of Microbiology, Vijaya College, Bangalore, India \\ ${ }^{2}$ Department of Biotechnology, Mother Teresa Women's University, Kodaikanal, India \\ *Corresponding author
}

\begin{tabular}{ll}
\hline & A B S T R A C T \\
\cline { 2 - 2 } $\begin{array}{l}\text { Keyw ords } \\
\text { MDR, }\end{array}$ & $\begin{array}{l}\text { A multiple drug resistant (MDR) bacteria are a class of bacteria which is resistant } \\
\text { to different classes of antibiotics and cause severe complications in humans as well } \\
\text { aseudomonas } \\
\begin{array}{l}\text { aeruginosa, } \\
\text { rRNA, }\end{array}\end{array}$ \\
$\begin{array}{l}\text { Antibiotics. } \\
\text { antimicrobial resistance patterns of } P \text {. aeruginosa clinical isolates obtained from } \\
\text { hospitalized patients. The results confirmed the occurrence of drug resistant strains } \\
\text { of } P \text {. aeruginosa. In this study, molecular identification of 16SrRNA was } \\
\text { performed and phylogenetic tree was constructed using a nearly complete sequence } \\
\text { within the 16S rDNA gene } P \text {. aeruginosa. The result shows that the isolate belongs } \\
\text { to the species } P \text {. aeruginosa. Amikacin, ciprofloxacin and Ceptazidine were found }\end{array}$ \\
$\begin{array}{l}\text { Accepted: } \\
\text { to be the most effective antimicrobial drugs. Therefore calls for a very judicious, } \\
\text { Available Online: } \\
\text { 10 July 2016 }\end{array}$ & $\begin{array}{l}\text { rational treatment regimens prescription by the physicians to limit the further } \\
\text { spread of antimicrobial resistance among the } P \text {. aeruginosa strains }\end{array}$ \\
\hline
\end{tabular}

\section{Introduction}

Pseudomonas aeruginosa founds in hospital environments and is a common problem in the environment since it is the second most common causative agent of nosocomial infections. The bacterium possesses a wide range of secretion systems, which secrets numerous proteins relevant to the pathogenesis of clinical strains (Hardie et al. 2009). Pseudomonas (Neu, 1983) are motile (one or more polar flagella), rod shaped aerobe and Gram-negative bacteria. They are found almost everywhere, in soil, water, plants and animals. $P$. aeruginosa is an opportunistic human pathogen most commonly affecting immuno-compromised patients.
It accounts for the majority of human infections. Pathogenic Pseudomonas is found throughout the body, most commonly in the urinary tract, respiratory tract, blood and wounds (Emori and Gaynes, 1993). $P$. aeruginosa is a type of bacterium that has the ability to develop resistance (Poirel et $a l ., 2004)$ to antibiotics rather rapidly over several generations. This resistance present in some strains makes $P$. aeruginosa very difficult to treat infected host, such as a human or other animal (Drenkard, 2003). Adding to its ability to develop drug resistance is its flexibility that allows it to thrive in various environments, especially medical environments and moist 
environments containing water. It acquires resistance genes and specific mutations that enhance its survival in the presence of antibiotics. Its genome was sequenced completely in 2000 and was recorded as having 6.3 million base pairs. Such a notably large genome encodes many proteins contributing to its versatility in adaptation, virulence function, and antimicrobial resistance (Livermore, 2002). To avoid the problem of variable phenotype for identification to provide more accurate species genotypes identification method is required. However, the taxonomic complexity, doubtful phylogeny, and lack of genomic sequence data of the dozens of species within the broad genus Pseudomonas present an obstacle to genotypic identification. The size of a $16 \mathrm{~S}$ rRNA gene is about 1,540 base pairs (bp).

In the past two decades, the rapid emergence of resistance to antimicrobial agents has been one of the most important clinical calamities. According to Fridkin et al. (1999) stated that the production of a variety of beta-lactamases, outer membrane permeability, and combinations of multiple mechanisms of resistance, the gram negative bacteria have acquired resistance to antibiotics such as extended-spectrum Cephalosporins, Monobactams, Carbapenems and beta-lactam-betalactamase inhibitor combinations. Survival study assessed in vitro susceptibility of commonly used antibiotics against clinical isolates of $P$. aeruginosa provides estimations of the rate of MDRPA infections (Karlowsky et al., 2003).

The MDR (Multiple Drug Resistance) bacteria (Cloete, 2003) were isolated from hospitals in Bangalore and through microbiological and biochemical analysis organism Pseudomonas was identified and isolated (Dotsch et al., 2009). In order to study the multiple drug resistance, antibiotic discs containing 8 different classes of antibiotics was used. By paper disc plate method the antibiotic resistance was confirmed. The present study was to study the resistance pattern of $P$. aeruginosa treated with various antibiotics which was isolated from Government Hospital in Bangalore, India.

\section{Materials and Methods}

\section{Source}

Samples were collected for investigation Government Medical Hospital, a centrally located Bangalore, Karnataka. Specimens were collected from various purulent swabs, infected urine and blood, hospital beds, linen, other furniture surfaces etc. patients who were hospitalized for more than one week duration. The samples were investigated for bacterial identification. Only one isolate was considered and include in the study.

\section{Isolation of Bacteria}

The samples were inoculated onto blood chocolate and MaCconkey agar plates. All plates were incubated both aerobically and anaerobically at $37^{\circ} \mathrm{C}$ overnight. Emergent colonies were identified according to standard bacteriological methods (Cheesbrough, 2006) and biochemical tests were carried out (Collee et al., 1996).

\section{Identification of Isolates using 16srRNA}

Molecular phylogeny of bacteria was determined by amplifying genomic $16 \mathrm{~S}$ rRNA region. Two primers specific to $16 \mathrm{~S}$ rRNA region used in this study were $519 \mathrm{~F}$ and $1385 \mathrm{R}$ in order to amplify approximately $850 \mathrm{bp}$ sequence of bacterial 16srRNA gene (Edward et al., 2004). The 
DNA sequences were analyzed using BLASTn (nucleotide Basic Local Alignment Search Tool) facility of National Centre for Biotechnology Information (NCBI). The BLAST results were used to find out evolutionary relationship of bacteria. Altogether twenty sequences, including sample were used to generate phylogenetic tree. The tree was constructed by using MEGA 5 software (Saitou and Nei, 1987).

\section{Determination of Antibiotic Sensitivity}

The test organism $P$. aeruginosa was taken with a sterile loop, suspended in sterile water. The turbidity of the suspension was adjusted to 0.5 McFarland's standard $(1.5 \times$ $\left.10^{8} \mathrm{CFU} / \mathrm{mL}\right)$. It was then spread on the surface of Mueller-Hinton agar (MHA) plate using sterile cotton swab. A total of 19 antibiotics in the following concentrations Amikacin, Netilmycin, Cefadroxil, Sparfloxacin, Ceftriaxone, Ciprofloxacin, Gentamycin, Cefotaxine, Cefoperazone, Lomefloxacin, Ampicillin+Sulbactam, Ceptazidine, Ampicillin, Chloramphenicol, Bacitracin, Erythromycin, Gentamycin, Polymyxin-B, Tetracycline. A stock antibiotic solution of $100 \mathrm{mg} / 100 \mathrm{ml}$ was prepared. A volume of $30 \mu \mathrm{l}$ of antibiotic was added to each well aseptically and the plate was incubated at $37^{\circ} \mathrm{C}$ for $24 \mathrm{hrs}$. The zone of inhibition was measured and with reference to the standard table it was determined whether the bacteria was sensitive, intermediate and resistant (Bauer et al., 1966).

\section{Results and Discussion}

\section{Isolation and Identification of Bacteria}

Based on the morphological and biochemical characters it was identified as Pseudomonas species. Pseudomonas sp. was gram negative, which shows positive result on catalase and oxidase, Gelatin liquefaction, $\mathrm{N}_{2}$ Reduction test. Organism shows motile, the bacteria showed bluish pigmented colony due to pyocyanin and colonies appeared circular $1 \mathrm{~mm}$ in diameter flat and soft in consistency in Cetrimide Agar. Urease, Indole, Methyl Red, VogesProskauer and citrate test revealed as negative. In Blood Agar, colonies show colourless zone due to beta hemolysis. In Mac Conkey agar plate, colonies appeared colourless indicated Pseudomonas sp. as nonlactose fermemter respectively. Hence to identify and confirm the Pseudomonas sp. at molecular level, 16S rRNA gene region was amplified and sequenced. Genomic DNA was extracted from Pseudomonas sp. by the standard method. PCR amplification of $16 \mathrm{~S}$ rRNA gene region by using universal primer, the obtained PCR product resulted in 1451 bp. By using BLAST analysis, 98 sequences of NCBI data gave $99 \%$ similarity. Phylogenetic tree generated by NCBI tool proves that this organism genetically related with other organisms (Fig. 1). On the basis of the position of sequence of the given bacterial samples in the phylogenetic tree, the closest similarity for the sample labeled as Pseudomonas was found to be Pseudomonas aeruginosa.

\section{Determination of Antibiotic Sensitivity}

The zone of inhibition was observed (Fig2) and measured. $P$. aeruginosa isolates showed maximum resistance pattern to Ampicillin, Chloramphenicol, Bacitracin, Erythromycin, Gentamycin, Tetracyclin, Polymyxin B and Ciprofloxacin and sensitive to amikacin, Ciprofloxacin, Ceptazidine and intermediate to Ceftriaxone, Gentamycin, Cefoperazone respectively. The resistance pattern of the $P$. aeruginosa to various antibiotics tested was shown (Table 1). The emergence of infectious diseases poses a serious threat to public 
health worldwide, and the increasing rate of the appearance of antibiotic -resistant strains in a short period of time both Gram positive and Gram-negative microorganisms is a major public health concern (Levinston and Jawetz, 2000).

Table.1 Determination of Zone of Inhibition of $P$. aeruginosa against antibiotics

\begin{tabular}{|l|c|c|c|}
\hline Antibiotics & Zone of inhibition(mm) & S/I/R & Strength(mcg) \\
\hline Amikacin & 17 & $\mathrm{~S}$ & $30 \mathrm{mcg}$ \\
\hline Netilmycin & 12 & $\mathrm{R}$ & $30 \mathrm{mcg}$ \\
\hline Cefadroxil & 0 & $\mathrm{R}$ & $30 \mathrm{mcg}$ \\
\hline Sparfloxacin & 12 & $\mathrm{R}$ & $5 \mathrm{mcg}$ \\
\hline Ceftriaxone & 17 & $\mathrm{I}$ & $30 \mathrm{mcg}$ \\
\hline Ciprofloxacin & 25 & $\mathrm{~S}$ & $5 \mathrm{mcg}$ \\
\hline Gentamycin & 14 & $\mathrm{I}$ & $10 \mathrm{mcg}$ \\
\hline Cefotaxine & 0 & $\mathrm{R}$ & $30 \mathrm{mcg}$ \\
\hline Cefoperazone & 20 & $\mathrm{I}$ & $75 \mathrm{mcg}$ \\
\hline Lomefloxacin & 16 & $\mathrm{R}$ & $5 \mathrm{mcg}$ \\
\hline Ampicillin+Sulbactam & 0 & $\mathrm{R}$ & $25 \mathrm{mcg}$ \\
\hline Ceptazidine & 18 & $\mathrm{~S}$ & $20 \mathrm{mcg}$ \\
\hline Ampicillin & 6 & $\mathrm{R}$ & 10 \\
\hline Chloramphenicol & 4 & $\mathrm{R}$ & 30 \\
\hline Bacitracin & 0 & $\mathrm{R}$ & 30 \\
\hline Erythromycin & 0 & $\mathrm{R}$ & 15 \\
\hline Gentamycin & 2 & $\mathrm{R}$ & 10 \\
\hline Polymyxin-B & 7 & $\mathrm{R}$ & $300 \mathrm{Units}$ \\
\hline Tetracycline & 8 & 30 \\
\hline
\end{tabular}

Fig.1 Phylogenetic tree for Pseudomonas aeruginosa using partial 16S rRNA gene sequence

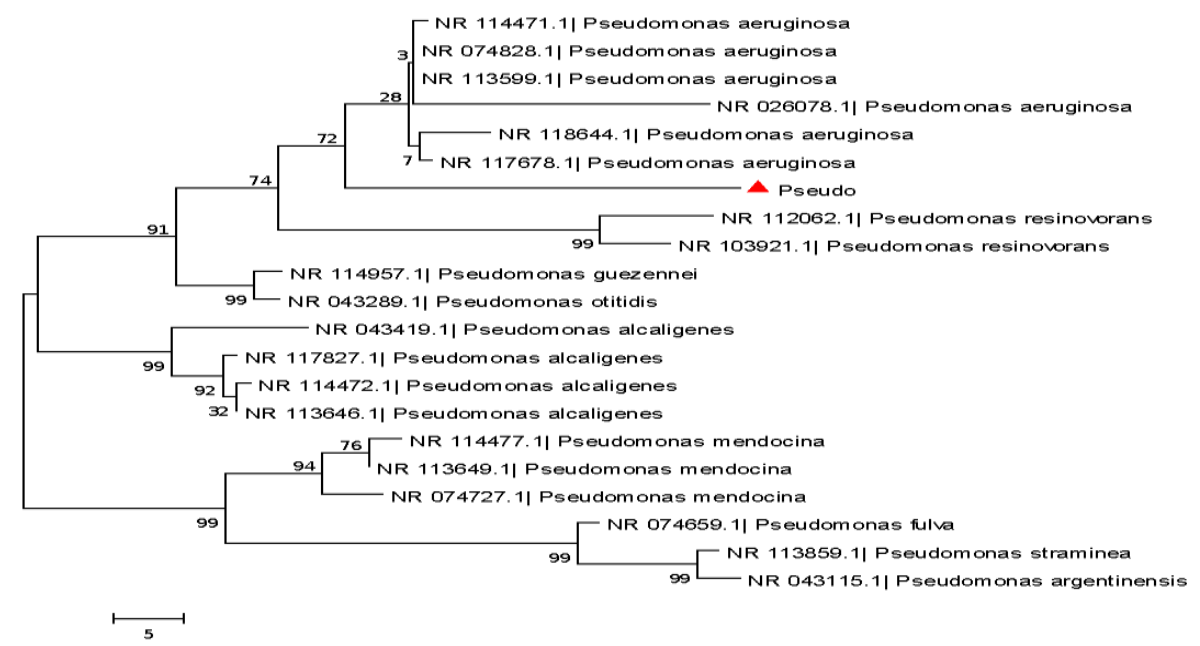


Fig.2 Antibiotic sensitivity test of $P$. aeruginosa

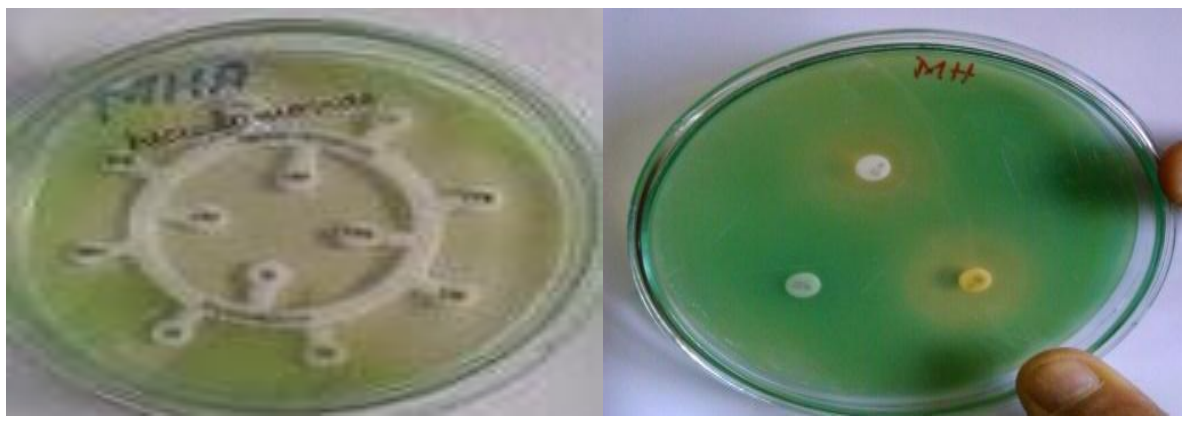

Treatment of infectious diseases becomes more challenging with each passing year. This is especially true for infections caused by the opportunistic pathogen $P$. aeruginosa, with its ability to rapidly develop resistance to multiple classes of antibiotics (Aloush et al., 2006). The ability of $P$. aeruginosa to survive on minimal nutritional requirements and to tolerate a variety of physical conditions has allowed this organism to persist in both community and hospital settings. $P$. aeruginosa presents a serious therapeutic challenge for treatment of both community-acquired and nosocomial infections, and selection of the appropriate antibiotic to initiate therapy is essential to optimizing the clinical outcome. Unfortunately, selection of the most appropriate antibiotic is complicated by the ability of $P$. aeruginosa to develop resistance to multiple classes of antibacterial agents, even during the course of treating an infection (Dimatatac, 2006). A more accepted approach is to treat serious $P$. aeruginosa infections with a combination of antibacterial agents. Although synergistic interactions are an important aspect for some drug combinations, the primary focus of combination therapy against $P$. aeruginosa is preventing the emergence of resistance.

In conclusion, this study illustrated that the Pseudomonas aeruginosa strain which was obtained from hospital environment were resistant to various antibiotics. The high rate of antibiotic resistance among $P$. aeruginosa strains is very alarming and can be responsible for serious infections. So identification of more such strains and taking efforts to reduce the rate of transfer between different strains are important goal for treatment of $P$. aeruginosa infections in future.

\section{References}

Aloush, V., Navon-Venezia, S., Seigman-Igra, Y., S. Cabili, Carmeli, Y. 2006. Multidrug-resistantPseudomonas aeruginosa: risk factors and clinical impact. Antimicrob. Agents Chemother., 50: 43-48.

Bauer, A.W., Kirby, W.M., J.C. Sherris and Turck, M. $1966 . \quad$ "Antibiotic susceptibility testing by a standardized single disk method," American J. Clin. Pathol., 45: 493-496.

Cheesbrough, M. 2006. District laboratory practice in tropical countries, part 2. Cambridge University Press, Cambridge, UK, London, 137-150.

Cloete, T.E. 2003. "Resistance mechanisms of bacteria to antimicrobial compounds," Int. Biodeterioration and Biodegradation, 51: 277-282.

Collee, J.G., R.S. Miles and Watt, B. 1996. Tests for identification of bacteria. In: Collee JG, Duguid JP, Fraser AG, Marmion BP, eds. Mackie and MacCartney Practical Medical Microbiology. 14th ed. New York: 
USA: Churchill Livingstone; p. 131149.

Dimatatac, E.L., Alejandria, M.M., Montalban, C., Pineda, C., C. Ang and Delino, R. 2003. Clinical outcomes and costs of care of antibiotic resistant Pseudomonas aeruginosa infections. Philipp. J. Microbiol Infect Dis., 32:159-167.

Dotsch, A., Becker, T., Pommerenke C., Magnowska, Z.L. Jansch and S. Haussler. 2009. Genomewide identification of genetic determinants of antimicrobial drug resistance in Pseudomonas aeruginosa. Antimicrob. Agents Chemother., 53: 2522-2531.

Drenkard, E. 2003. Antimicrobial resistance of Pseudomonas aeruginosa biofilms, Microbes and Infection, 5: 1213-1219.

Emori., T.G., Gaynes, R.P. 1993. An overview of nosocomial infections, including the role of the microbiology laboratory. Clin. Microbiol. Rev., 6: 428-442.

Fridkin, S., Steward, C., Edwards, J., Pryor, E., McGowan, J., Archibald, L., et al. 1999. Surveillance of Antimicrobial Use and Antimicrobial Resistance in United States Hospitals: Project ICARE Phase 2. Clin. Infectious Dis., 29: 245-252.

Gaby, W.L., Free, E. 1958. Occurrence and identification of non-pigmented strains of $P$. aeruginosa in the clinical laboratory. J. Bact., 65: 746.

Girlich, D., T. Naas and Nordmann, P. 2004. Biochemical characterization of the naturally occurring oxacillinase OXA50 of Pseudomonas aeruginosa. Antimicrob. Agents Chemother., 48: 2043-2048.

Karlowsky, J.A., Draghi, D.C., Jones, M.E.,
Thornsberry, C, I.R. Friedland and Sahm, D.F. 2003. Surveillance for antimicrobial susceptibility among clinical isolates of Pseudomonas aeruginosa and Acinetobacter baumannii from hospitalized patients in the United States, 1998 to 2001. Antimicrob. Agents Chemother., 47: 1681-1688.

Levinson, W., Jawetz, E. 2000. "Gram negative rods related to enteric tract," in Medical Microbiology and Immunology (Examination and Board Review),Lange Medical Books/McGraw-Hill, Toronto, Canada, 6th edition, pp. 107-126.

Livermore, DM. 2002. Multiple mechanisms of antimicrobial resistance in Pseudomonas aeruginosa: our worst nightmare. Clin. Infec. Dis., 34: 634640.

Moore, E., Arnscheidt, A., Kruger, A., C. Strompl and Mau, M. 2004. Simplified protocols for the preparation of genomic DNA from bacterial cultures. Mol. Microbiol. Ecol. Manual, 2nd edition. 1. 01: 3-18.

Neu, H.C. 1983. "The role of Pseudomonas aeruginosa in infections," J. Antimicrob. Chemother., 11: 1-13.

Poirel, L., Magalhaes, M., M. Lopes and Nordmann, P. 2004. "Molecular analysis of metallo-beta-lactamase gene bla (SPM-1) surrounding sequences from disseminated Pseudomonas aeruginosa isolates in Recife, Brazil. Antimicrob. Agents and Chemother., 48: 1406-1409.

Saitou, N., Nei, M. 1987. The neighborjoining method: A new method for reconstructing phylogenetic trees. Mol. Biol. Evol., 4: 406-425.

\section{How to cite this article:}

Madhumita Ghosh Dastidar and M. Razia. 2016. Isolation of Multiple Drug Resistant (MDR) Bacteria from Hospital Environment. Int.J.Curr.Microbiol.App.Sci. 5(7): 48-53. doi: http://dx.doi.org/10.20546/ijcmas.2016.507.003 